\title{
Transition course in psychiatric nursing as an intervention in facilitating students' perceived preparedness in handling patients with mental illness
}

\begin{abstract}
This study investigated the impact of training as intervention in facilitating nursing students' perceived readiness in handling patients in their psychiatric nursing practicum. A total of 89 nursing students across three school years served as participants of the study. Results of self-assessment tests that were given before and after the three-day intensive transition course show significant difference in the perceived competence of the students to handle mental health patients. Feelings of anxiety in doing clinical work significantly decreased after the training. The students perceived the transition course as an enormous help in equipping them with the appropriate skills, precise knowledge, and sufficient psychological readiness that are necessary in facing up to the challenges of actual clinical practice. Results of the study distinctly underscore the value of training psychiatric nursing students before exposing them to the real-world clinical practice. Practical implications of the results are also discussed.
\end{abstract}

Keywords: psychiatric nursing, mental health nursing, clinical practicum, student perception, student preparedness, training
Volume 2 Issue I - 2017

Ana Joy P Mendez

School of Nursing and Health Sciences, University of Guam, Guam

Correspondence: Ana Joy P Mendez, Assistant Professor School of Nursing and Health Sciences, University of Guam, Guam,Tel I67I 4880 932,Email dr.anajoymendez@yahoo.com

Received: October 25, 2016 | Published: January 04, 2017

\section{Introduction}

Nursing students get exposed to dealing with mental health patients in their psychiatric nursing practicum. This clinical practice is considered an essential part of their nursing education as this prepares them to be able to "know" and "do" the mental health clinical principles in practice. ${ }^{1}$ However, students may fear the experience especially if they feel unprepared for the complex practice situations that the practicum presents. ${ }^{2}$ Studies on students' mental health nursing experiences show that although the practice may help them gain knowledge and skills ${ }^{3}$ in the end, it also makes them see the gap between theory and actual practice ${ }^{1,4}$ as well as experience anxiety brought about by their lack of sufficient knowledge ${ }^{1,2}$ at the outset.

It is necessary that nursing students be adequately equipped for real-life clinical practice ${ }^{4}$ as the mental health praxis holds a critical role in promoting mental health, preventing problems associated with it, and treatment of psychiatric disorder among members of society. One sure way of addressing this is by giving them the appropriate training the students need. As it is the aspiration of any academic institution that its students' academic qualification be improved ${ }^{5}$ it is thus not surprising that it uses trainings as a form of intervention to ensure competence among its learners.

Training is defined as an activity whose goal is to advance knowledge, attitudes, and skills so as to increase and enhance learner performance. ${ }^{6}$ This paper posits that sufficient training makes students more psychologically ready to step into the real world of practice; and such feeling of adequate preparedness actually empowers them in the process.

Literature shows the importance and benefits of training ${ }^{6,7}$ not just to the learner but to the organizations (e.g., hospital) as well. ${ }^{8}$ Documented body of evidence shows that training activities positively impact performance of individuals. ${ }^{7}$ As such, many organizations continually invest on training their people knowing that it equips their staff $^{9}$ as well as give them a competitive advantage along the way. The subsequent part of this paper discusses the values of training.

\section{Benefits of training}

Training is systematic method to learning and development that advances the effectiveness of an individual, a team, or an organization. ${ }^{10}$ In this section we discuss three benefits that training may give: improvement of performance, facilitation of learning, as well as enhancement of self-efficacy among the learners.

\section{Training improves performance}

Trainings result to better quality performance. ${ }^{7}$ One study found that even a simplified two-hour training method could improve the cardiopulmonary resuscitation quality and retention skills of medical professionals. ${ }^{11}$ In-service nursing education was also found to heighten nurses' communication performance in clinical practice. ${ }^{12}$ Outside the clinical practice Sultana et al. ${ }^{13}$ Found that appropriate training enhances the performance, competencies, and skills of some telecommunication employees in Pakistan. Shah et al. ${ }^{14}$ on the other hand, observed that on-the-job training had a positive impact on the performance of employees of microfinance banks in the same country. As such, training is a vital and key factor in improving learner performance.

\section{Training facilitates learning}

Individuals store and retrieve information or come up with novel and creative ideas to solve problems and make decisions when being given new information through training. As such, besides improving performance, trainings may also impact learner's declarative and procedural knowledge. It may even heighten strategic knowledge so that the learner may know when, where, and how a strategic knowledge may be applied. ${ }^{7}$ In a study conducted by Roh et al. ${ }^{15}$ which 
looks into effectiveness of integrated simulation-based resuscitation skills training among nursing students, it was found that knowledge significantly improved after the students were given training. Trainings lead to new ideas that may also result to performance creativity as well as excellent execution of work. ${ }^{16}$ Additionally, trainings also facilitate consistency in performance among those trained across conditions. ${ }^{7}$

\section{Training enhances self-efficacy}

Evidence from the literature show that training may also boost learner's self-efficacy. Self-efficacy is defined by Bandura ${ }^{17}$ as belief in one's capabilities. It was found that nurses given training on communication have better self-efficacy than before their training. ${ }^{12,18}$ Training was also found to significantly improve the internet selfefficacy of computer students in the United States of America. ${ }^{19}$ Even training on mindfulness was found to effectively increase self-efficacy of cancer patients in Iran. ${ }^{20}$ With greater confidence, learners may easily accomplish their task successfully. ${ }^{21}$ This study investigates the impact of training on learners' perceived preparedness to handle mental health patients. It seeks to know if the training given them affects their perceived ability, knowledge, and sense of competence in dealing with psychiatric patients.

\section{Methods}

\section{Sample}

A total of 89 students from the University of Guam Nursing program participated in the activity. They were from three cohort groups who took the psychiatric nursing course in the years 2012 , 2013, and 2014

\section{Measure}

The study utilized two scales: 15 -item self-assessment scale and 7-item post-practicum evaluation scale.

The 15-item self-assessment scale is an 11-point likert questionnaire with least competent on one end and most competent on the other. It measures the students' perceived competence in two areas: knowledge and skill on handling mental health patients. The scale has a Chronbach's Alpha $=0.98$.

The 7-item post-practicum evaluation scale is a 7-point likert questionnaire with strongly disagree on one end and strongly agree on the other. It measures the students' perceived proficiency in two areas: knowledge and application of knowledge in the field. Higher score means better knowledge and application of knowledge in the clinical practice. The scale has a good internal consistency reliability with Chronbach's Alpha $=0.88$.

\section{Procedure}

The students were made to undertake a three-day intensive transition course prior to exposing them to handling psychiatric clients in acute clinical settings. The course thoroughly discussed various modalities of interventions and approaches and provided practice scenarios so as to give students the "feel" and "hands on" opportunity of handling cases before the actual clinical practicum.

Expected skills that would be acquired after the workshop are therapeutic communication skills, basic assessment skills, identification of behaviour needing further evaluation, and application of appropriate interventions for specific behaviours. Students are also expected to describe mental health, nursing roles, technological advancement, and treatment modalities; identify theories of care management, demonstrate the use of self (nurse) as a tool in assisting clients in the recovery process.

The students answered the 15 -item self-assessment scale before and after the three-day intensive training. At the end of one semester practicum, the same students answered the post-practicum evaluation.

One way analysis of variance, t-test, central tendencies, and other statistical techniques were used in analysing the data.

\section{Results}

Results of the study affirmed the positive impact of training on students' perceived preparedness in handling psychiatric patients. This section details this statement. One way analysis of variance showed that the three cohort groups did not differ in their assessment of their knowledge and skills in handling mental health patients before and after the transition course with $F(2,84)=1.761$ and $\mathrm{p}>0.01$ and $F(2,84)=3.915$ and $\mathrm{p}>0.01$ respectively. Post hoc analysis showed that before the training, the 2014 cohort felt the least competent $(M=65.09$, $S D=11.34)$ followed by the 2013 cohort $(M=67.68, S D=9.49)$, with cohort 2012 feeling the most competent $(M=69.83, S D=8.68)$. After training, however, it is cohort 2013 which felt most competent $(M=130.88, S D=6.72)$ followed by cohort $2012 \quad(M=130.03$, $S D=8.604)$, with cohort 2014 feeling the least competent $(M=124.94$, $S D=10.46$ ).

Test for differences on the self-assessment before and after the transition course indicated that there is a significant difference in the students' perceived competence before and after the training with $t(172)=-41.77$ and $\mathrm{p}<0.05$. The students felt more proficient in terms of knowledge and skill in dealing with psychiatric patients after the three-day intensive training than before it. Anxiety level also significantly decreased with $t(172)=-37.24$ and $\mathrm{p}<0.05$. Where before the training students experienced much anxiety to face clinical work $(M=8.99, S D=1.06)$, such feeling significantly lessened after the transition course $(M=2.26, S D=1.31)$.

Post practicum evaluation showed that $97 \%$ of the students believed they were able to gain knowledge from the intensive threeday transition course that helped them better understand problems of clients, know how to better communicate with patients, and maintain professionalism and compassion in the clinical practice. Ninety four percent $(94 \%)$ of them articulated that they were able to put into clinical practice the learning's gained from the training in employing apt strategies during challenging situations, in evaluating therapeutic actions of other caregivers, and in coping with psychiatric emergency situations. Among the participants of the study, 91\% stated that the transition course increased their confidence in interaction with clients, $86 \%$ declared the training helped lessen their anxiety level, and $72 \%$ expressed that the course helped increase their satisfaction with the clinical practice. Seventy three percent (73\%) of them revealed that the transition course taught them when to anticipate what is to be expected.

Additionally, $69 \%$ of the participants pronounced that the training gave them the adeptness to encourage and increase participation and compliance from patients as well as provided them the ability to increase the overall quality of the care provided to clients. All of the student participants recommended that the transition course they were made to go through be experienced by the incoming students who shall take up the course on psychiatric nursing. That is because they 
believe that the three-day intensive training was a huge help to them as learner-clinical practitioner.

\section{Discussion}

The results of the study clearly highlight the value of training psychiatric nursing students before exposing them to real-world clinical practice. This kind of intervention aptly equips the students with the appropriate skills, with precise knowledge, and with sufficient psychological readiness, providing them with the necessary arms and weapons to deal with the challenges of actual clinical environment As such "preparedness" here refers to being ready to face mental health patients psychologically (e.g., confidence, less anxiety) as well as in terms of skill and knowledge. One, thus, cannot discount the legitimacy of trainings in the nursing practice.

\section{Conclusion}

This paper posits that sufficient training makes students more psychologically ready to step into the real world of practice; and such feeling of adequate preparedness actually empowers them in the process. Findings of the study point to the significance of training in preparing and empowering the learner, making him/her to be more effective in providing mental health care to psychiatric patients. This makes trainings indispensable and strategic in terms of developing core competencies that are tools in the field of clinical practice.

Practical implications of the results of the study points toward the nursing academic institutions' not being daunted in investing on in appropriate trainings for their students. The investment would surely not go to waste as besides preparing them cognitively and psychologically, the activity may also serve as the academe's support to the students, and guiding them in their quest for excellence in the nursing profession. Lastly, the training which leads to satisfactory practicum experiences may also encourage the students to take on the road of psychiatric nursing as a future career path.

\section{Acknowledgements}

None.

\section{Conflict of interest}

The author declares no conflict of interest.

\section{References}

1. Sharif F, Masoumi S. A qualitative study of nursing student experiences of clinical practice. BMC Nursing. 2005;4(6)

2. Ewashen C, Lane A. Pedagogy, power and practice ethics: Clinical teaching in psychiatric/mental health settings. Nursing Inquiry. 2007;14(3):255-262

3. Hung B, Huang X, Lin M. The first experiences of clinical practice of psychiatric nursing students in Taiwan: A phenomenological study. Journal of Clinical Nursing. 2009;18(22):3126-3125.

4. Houghton CE, Casey D, Shaw D, et al. Students'experience of implementing clinical skills in the real world of practice. J Clin Nurs. 2012;22(13-14):1961-1969.

5. Kianipour O, Hoseini B. Effectiveness of training the choice theory of Glasser to teachers on improvement of students'academic qualification. Journal of Educational and Instructional Studies in the World. 2012;2(2):117-123.
6. Edralin DM. Training: A strategic HRM function. Notes on Business Education. 2004;7(4):1-4.

7. Aguinis $\mathrm{H}$, Kraiger $\mathrm{K}$. Benefits of training and development for individuals and teams, organizations, and society. Annu Rev Psychol. 2009;60:451-474.

8. De Grip A, Sauermann J. The effect of training on productivity: The transfer of on-the-job training from the perspective of economics. Educational Research Review. 2003;8:28-36.

9. Edralin DM. Training and development practices of large philippine companies. Asia Pacific Business Review. 2011;17(2):225-239.

10. Goldstein IL, Ford K. Training in organizations: Needs assessment development and evaluation. 4th ed. Wadsworth, USA: Springer; 2012.

11. Allan KS, Wong N, Aves T, et al. The benefits of a simplified method for CPR training of medical professionals: A randomized controlled study. Resuscitation. 2013;84(8):1119-1124.

12. Hsu L, Chang W, Hsieh S. The effect of scenario-based simulation course training on nurses"communication competence and self-efficacy: A randomized controlled trial. Journal of Professional Nursing. 2015;31(1):37-49.

13. Sultana A, Irum $\mathrm{S}$, Ahmed $\mathrm{K}$, et al. Impact of training on employee performance: A study of telecommunication sector in Pakistan. Interdisciplinary Journal of Contempory Research in Business. 2012;4(6):646-661.

14. Shah SMA, Shah TA, Abbas SH. Impact of on-the-job training on employee performance (A case study of microfinance banks in District Khaipur). International Journal of Computers and Technology. 2014;13(5):4524-4529.

15. Roh YS, Lim E J, Issenberg SB. Effects of an integrated simulation-based resuscitation skills training with clinical practicum on mastery learning and self-efficacy in nursing students. Collegian. 2014;23(1):53-59.

16. Vemic J. Employee training and development and the learning organization. Economics and Organization:Series. 2007;4(2):209-216.

17. Bandura A. Cultivate self-efficacy for personal and organizational effectiveness. In EA Locke editor. Handbook of Principles of Organization Behavior. 2nd ed. New York, USA: Springer; 2009. p. $179-200$

18. Hsu L, Huang Y, Hsieh S. The effects of scenario-based communication training on nurses'communication competence and self-efficacy and myocardial infarction knowledge. Patient Educ Couns. 2014;95(3):356364.

19. Torkzadeh G, Van Dyke TP. Effects of training on internet selfefficacy and computer user attitudes. Computers in Human Behavior. 2002; 18(5):479-494.

20. Sanaei H, Hossini SA, Jamshidifar Z. Effectiveness of mindfulness training on self-efficacy of patients infected by breast cancer. ProcediaSocial and Behavioral Sciences. 2014;159:426-429.

21. Farooq M, Khan MA. Impact of training and feedback on employee performance. Far East Journal of Psychology and Business. 2011;5(1):23-33

22. Happell B, Gaskin CJ. The attitudes of undergraduate nursing students towards mental health nursing: A systematic review. Journal of Clinical Nursing. 2012;22(1):148-158.

23. Happell B. The importance of clinical experience for mental health nursing-Part 2: Relationships between undergraduate nursing students'attitudes, preparedness, and satisfaction. International Journal of Mental Health. 2008;17(5):333-340. 